\title{
Comparative Study to Evaluate Tolerability of Topical 5\% Minoxidil Novel Formulation and Alcohol-Based Conventional Solutions in Treatment of Androgenetic Alopecia in Indian Men: Randomized Double-Blind Study
}

Rashmi Sarkar · Suneel Vartak · Shivani Acharya · Nikhil Kumar Kursam •

Amey Mane $\cdot$ Suyog Mehta $\cdot$ Sujeet Narayan Charugulla (D)

Received: March 3, 2020 / Published online: April 10, 2020

(C) The Author(s) 2020

\section{ABSTRACT}

Introduction: Patients with androgenetic alopecia treated with alcohol-based minoxidil topical solutions often report local irritation, dryness, and redness of the scalp. We evaluate the in-use tolerance of $5 \%$ minoxidil novel formulation topical solution-test product (TP)—compared with 5\% minoxidil alcoholbased topical solutions-reference product 1 (RP1) and reference product 2 (RP2)-in Indian men with androgenetic alopecia.

Methods: In this randomized double-blind study, patients aged $\geq 18$ years with androgenetic alopecia were randomized 1:1:1 to apply TP, RP1, and RP2 twice daily for 30 days. The safety endpoints included mean hydration, mean redness, and mean scaling on scalp.

Digital Features To view digital features for this article go to https://doi.org/10.6084/m9.figshare.12029772.

R. Sarkar

Department of Dermatology, Maulana Azad Medical

College, New Delhi, India

S. Vartak

C.L.A.I.M.S. Pvt Ltd, Mumbai, Maharashtra, India

S. Acharya - N. K. Kursam · A. Mane - S. Mehta .

S. N. Charugulla (ه)

Dr. Reddy's Laboratories Pvt Ltd, Ameerpet,

Hyderabad, India

e-mail: sujeetnc@drreddys.com
Results: All screened patients $(N=100)$ were enrolled and randomized to TP $(n=33)$, RP1 $(n=33)$, or RP2 $(n=34)$. At day 30 , the mean (SD) hydration was significantly increased in patients treated with TP [9.74 (4.98)] but significantly reduced in patients treated with RP1 [3.28 (2.67)] or RP2 [3.03 (1.57)] ( $p$-value 0.001). The mean (SD) score for redness was significantly decreased in the TP group [0.01 (0.04)], ( $p$-value, 0.009$)$ at day 30 compared with baseline, while no change was observed in the RP1 [0.08 (0.13)] or RP2 [0.11 (0.17)] group. After 30 days of treatment, no significant difference was observed in the mean score of scaling in any of the three groups.

Conclusions: Twice daily application of 5\% minoxidil novel formulation for 30 days significantly improved hydration and reduced redness of the scalp. Hence, 5\% minoxidil novel formulation could be a safer alternative in treating men with androgenetic alopecia who are sensitive to alcoholic formulations.

Trial Registration: Clinical Trial Registry of India; CTRI/2018/11/016431.

Keywords: Androgenetic alopecia; Indian; Men; Minoxidil safety 


\section{Key Summary Points}

\section{Why carry out this study?}

Androgenetic alopecia is the most common type of dermatological disorder, affecting $58 \%$ of Indian men aged $30-50$ years.

Patients with androgenetic alopecia treated with alcohol-based minoxidil topical solutions often report local irritation, dryness, and redness of the scalp, which are more common in 5\% formulations compared with $2 \%$ formulations, as a higher percentage of propylene glycol is used in 5\% than $2 \%$ formulation to solubilize minoxidil.

This randomized double-blind study evaluated the in-use tolerance of 5\% minoxidil novel formulation topical solution [test product (TP); $n=33$ ] compared with 5\% minoxidil alcoholbased topical solutions [reference product 1 (RP1) Regaine 5\% $n=33$ and reference product 2 (RP2) Mintop Forte 5\% $n=34$ ] in Indian men (aged $\geq 18$ years) with androgenetic alopecia.

\section{What was learned from the study?}

Twice daily application of $5 \%$ minoxidil novel formulation for 30 days significantly improved hydration and reduced redness of the scalp, whereas alcohol-based formulations increased dryness and redness of the scalp.

A 5\% minoxidil novel formulation could be a safer and most satisfactory alternative to alcoholic formulations in treating men with androgenetic alopecia.

\section{INTRODUCTION}

Androgenetic alopecia is the most common type of dermatological disorder, affecting 58\% of Indian men aged $30-50$ years [1]. It is a common cause of hair loss at a young age and leads to psychological distress/morbidity, low self-esteem, and in some cases, anxiety and depression [2, 3]. In about half of the Indian male population with androgenetic alopecia, its severity is grade I to III, which could be potentially treated with either oral or topical medications [1]. The current treatment options for androgenetic alopecia are limited to minoxidil ( $2 \%$ and $5 \%)$ and finasteride $(1 \mathrm{mg} /$ day), which are the treatments approved by the Food and Drug Administration for male androgenetic alopecia [4, 5]. The $2 \%$ topical solution of minoxidil has been reported to be superior to finasteride in terms of improved mean change in total hair count from baseline to 12 months (2\% minoxidil, 36.1 hairs $/ \mathrm{cm}^{2}$; finasteride, 19.6 hairs $/ \mathrm{cm}^{2}$ ) in the treatment of male androgenetic alopecia [6].

Minoxidil topical solutions, $2 \%$ and $5 \%$, are the widely used treatment option for male androgenetic alopecia. The vehicles used in minoxidil topical solutions are water, alcohol, and propylene glycol [4]. Propylene-glycolcontaining preparations are known to cause symptoms such as scalp sensitivity, itching, burning, and local irritation, and it has been evidenced in literature that patients sensitive to propylene glycol are most likely susceptible to contact dermatitis [7]. Evidence suggests that patients with androgenetic alopecia treated with alcohol-based minoxidil topical solutions often report local irritation of scalp (pruritus, itching, and burning), dryness, and redness [8]. It is also reported that the occurrence of these adverse events (AEs) is more common with 5\% formulations compared with $2 \%$ formulations, as a higher percentage of propylene glycol is used in $5 \%$ than $2 \%$ formulation to solubilize minoxidil [9]. Note that the effect of minoxidil treatment can be expected in 6-8 weeks, and to maintain the effects, the treatment must be applied continuously for 6-12 months [4, 5]. The AEs reported due to vehicle often impact negatively the patient's compliance with the treatment for longer time periods [10]. Hence, to provide treatment options for patients sensitive to alcoholic formulations and to improve the cosmetic properties ensuring compliance 
and acceptability, minoxidil topical solutions free from propylene glycol could be a better alternative option. In a recent double-blind study in men with androgenetic alopecia, treatment with propylene-glycol-free minoxidil foam demonstrated lesser incidence of pruritus (1\%) compared with men treated with minoxidil alcoholic formulations (4\%) [4].

In this study, we evaluate the in-use tolerance of 5\% minoxidil novel formulation topical solution [test product (TP)] compared with alcohol-based topical solutions [reference product 1 (RP1) Regaine 5\% and reference product 2 (RP2) Mintop Forte 5\%] in Indian men with androgenetic alopecia.

\section{METHODS}

\section{Study Design and Patients}

This randomized double-blind three-arm study of 5\% minoxidil novel test formulation (TP containing $2 \% \mathrm{v} / \mathrm{v}$ ethanol, manufactured by Dr. Reddy's Laboratories Ltd) and 5\% minoxidil alcohol-based reference formulations (RP1 containing 30\% v/v ethanol and RP2 containing $40 \% \mathrm{v} / \mathrm{v}$ ethanol; manufactured by Johnson \& Johnson Ltd and Dr. Reddy's Laboratories Ltd, respectively) was conducted to compare in-use tolerance of TP, RP1, and RP2 in Indian men with androgenetic alopecia. The study consisted of a screening phase and a 30-day treatment phase.

The study protocol and informed consent form were reviewed and approved by the Independent Ethics Committee and Institutional Review Board (registration no. ECR/98/Inst/ MH/2013/RR-16; Yash Society's Sujata Birla Hospital Ethics Committee, Nashik Road). The study was in compliance with the ethical principles of the Declaration of Helsinki and was conducted in accordance with the International Council for Harmonization, Good Clinical Practice guidelines, and schedule Y. This study is registered prospectively at Clinical Trial Registry of India (CTRI/2018/11/016431).

Men aged $\geq 18$ years with presence of androgenetic alopecia as measured by Norwood Hamilton Scale grade $>3$ were included in this study. Men who had scarring of the scalp, disease of the scalp/hair, cardiac abnormalities, or abnormal blood pressure were excluded. Additionally, patients who had known sensitivity to minoxidil or had hypersensitivity to any cosmetic products were also excluded from the study. Other exclusion criteria were systemic or cutaneous disease and use of systemic or topical medication, which may interfere with the study treatment.

\section{Study Assessments}

The primary safety endpoints were mean hydration, mean redness, and mean scaling on scalp at baseline visit, day 15 , and day 30 . For all the assessments, the bald area was divided into four areas and the average values are reported. The hydration of the scalp (stratum corneum) was assessed by using a MoistureMeter SC to measure the electrical properties of the skin. The measured capacitance of the scalp was directly proportional to the water content in the scalp. A score $<20$ indicates dry skin, 20-40 indicates normal skin, and $>40$ indicates a well-hydrated skin. The redness and scaling on the scalp were measured using a five-point scale (0: none, 1 : very slight, 2 : slight, 3 : moderate, 4 : severe).

Other safety endpoints included the proportion of patients with prickling, itching, and burning sensation and overall satisfaction in terms of skin tolerance and fragrance at days 15 and 30. A self-evaluation questionnaire was used to capture in-use skin tolerance (prickling, itching, and burning sensation). A score of 1, 2, and 3 indicated slight, moderate, and severe symptoms, respectively.

\section{Treatment, Randomization, and Blinding}

Patients were randomized (1:1:1) to TP, RP1, or RP2 and were asked to apply $1 \mathrm{~mL}$ of the solution twice daily (morning and night) for 30 days evenly on the areas where the hair was thin/ bald. To randomize the study patients, a randomization sheet was generated using an MS Office 365 excel sheet (function: RAND), by QA 
Department. The investigator and the patients were blinded to the treatment.

\section{Statistical Analysis}

No sample size calculation was carried out, as this is an in-use tolerance study. According to the IS 4011:2018 recommendations for cosmetics, the in-use test was performed on 15 patients for 15 days. The safety parameters were compared between the groups using Student's $t$ test and $\chi^{2}$ test. The safety assessments were analyzed in safety population. Statistical software SPSS version 10.0 [SPSS Inc. (1999), Chicago, IL] was used for statistical evaluation.

\section{RESULTS}

\section{Patient Disposition and Baseline Characteristics}

The study was conducted at Yash Society's Sujata Birla Hospital, Nashik, India between December 2018 and February 2019. A total of 100 patients were screened, and all were enrolled and randomized to RP1 $(n=33)$, RP2 $(n=34)$, or TP $(n=33)$. Of these, 94 patients completed the study (RP1: $n=30$; RP2: $n=33$; and TP: $n=31$ ) while 6 patients discontinued the study. The reason for study discontinuation was loss to follow-up. The mean age of the patients was 39.52 years (RP1: 38.93 years; RP2: 39.79 years; TP: 39.84 years). The baseline characteristics were uniformly distributed among the groups (Table 1).

\section{Safety}

\section{Hydration on Scalp}

At baseline, the mean (SD) moisture content of the scalp was 4.76 (3.45), 4.25 (2.98), and 4.91 (4.16) in patients treated with RP1, RP2, and TP, respectively. At day 15, a decrease in the mean (SD) moisture content of the scalp was observed in patients treated with RP1 [3.75 (2.78); pvalue, 0.001$]$ and RP2 [3.90 (3.80; $p$-value, $0.341)]$. A significant increase ( $p$-value, 0.001$)$ in the moisture content of $81.7 \%$ was observed in
Table 1 Patient demographics and baseline characteristics

\begin{tabular}{llll}
\hline Characteristic & $\begin{array}{l}\text { RP1 } \\
(\boldsymbol{n}=\mathbf{3 0})\end{array}$ & $\begin{array}{l}\text { RP2 } \\
(\boldsymbol{n}=\mathbf{3 3})\end{array}$ & $\begin{array}{l}\text { TP } \\
(\boldsymbol{n}=\mathbf{3 1})\end{array}$ \\
\hline $\begin{array}{l}\text { Age, years, } \\
\text { mean }\end{array}$ & 38.93 & 39.79 & 39.84 \\
$\begin{array}{l}\text { Skin type } \\
\text { Normal }\end{array}$ & $5(16.67)$ & $7(21.21)$ & $9(29.03)$ \\
Dry & $20(66.67)$ & $17(51.51)$ & $13(41.93)$ \\
Oily & $5(16.67)$ & $9(27.27)$ & $9(29.03)$
\end{tabular}

Scalp dandruff

$\begin{array}{llll}\text { Yes } & 13(43.33) & 7(21.21) & 8(25.81)\end{array}$

Lice

Yes

$$
0
$$

0

0

White hair

Yes $\quad 13(43.33) \quad 13(39.39) \quad 13(41.93)$

Use of hair dye

Yes $\quad 5(16.67) \quad 3(9.09) \quad 5(16.13)$

Hair fall

$\begin{array}{llll}\text { Normal } & 2(6.67) & 1(3.03) & 1(3.03) \\ \text { Moderate } & 28(93.33) & 31(93.94) & 28(90.32) \\ \text { Severe } & 0 & 1(3.03) & 2(6.45)\end{array}$

Androgenetic alopecia grade

\begin{tabular}{llll} 
III & $12(40.0)$ & $15(45.45)$ & $12(38.71)$ \\
IV & $7(23.33)$ & $6(18.18)$ & $9(29.03)$ \\
V & $2(6.67)$ & $2(6.06)$ & $3(9.68)$ \\
VI & $9(30)$ & $10(30.30)$ & $6(19.35)$ \\
VII & 0 & 0 & $1(3.23)$ \\
\hline
\end{tabular}

All values presented as $n$ (\%) unless specified RP1 5\% Regaine, RP2 5\% Mintop Forte, TP test minoxidil $5 \%$ novel formulation

patients treated with TP [8.92 (4.32)]. At day 30, a significant decrease ( $p$-value, 0.001 ) in the mean (SD) moisture content of the scalp was observed in patients treated with RP1 [3.28 (2.67)] and RP2 [3.03 (1.57)]. A significant 


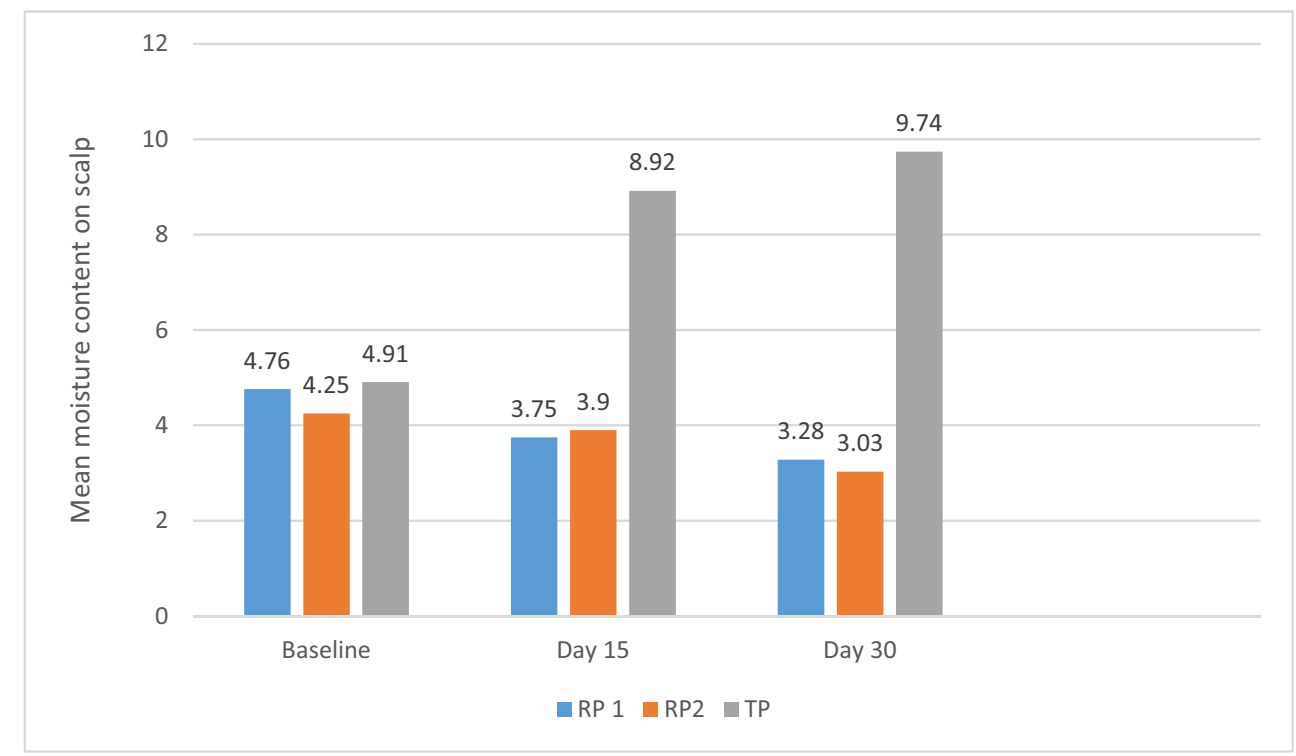

\begin{tabular}{llcl}
\hline & \multicolumn{1}{l}{ RP1 $(\mathbf{n}=\mathbf{3 0})$} & $\mathbf{R P 2}(\mathbf{n}=\mathbf{3 3})$ & $\mathbf{T P}(\mathbf{n}=\mathbf{3 1})$ \\
\hline & \multicolumn{4}{l}{ Mean $(\mathbf{S D})$ moisture content on the scalp } & \\
\hline Baseline & $4.76 \pm 3.45$ & $4.25 \pm 2.98$ & $4.91 \pm 4.16$ \\
Day 15 & $3.75 \pm 2.78$ & $3.90 \pm 3.80$ & $8.92 \pm 4.32$ \\
Day 30 & $3.28 \pm 2.67$ & $3.03 \pm 1.57$ & $9.74 \pm 4.98$ \\
\hline & \multicolumn{4}{l}{ Mean (SD) change from baseline } & \\
\hline Day 15, (p value) & $*-1.01 \pm 1.47$ & $-0.35 \pm 2.08$ & $* 4.01 \pm 4.29$ \\
& $(0.001)$ & $(0.341) \mathrm{NS}$ & $(0.001)$ \\
Day 30, (p value) & $*-1.47 \pm 2.01$ & $*-1.22 \pm 2.31$ & $* 4.83 \pm 5.14$ \\
& $(0.001)$ & $(0.004)$ & $(0.001)$ \\
\hline
\end{tabular}

NS, not significant; * significant.

RP1, 5\% Regaine; RP2, 5\% Mintop Forte; TP, test minoxidil 5\% novel formulation.

Fig. 1 Mean change from baseline in moisture content of scalp after treatment with minoxidil

increase in the moisture content of $98.4 \%$ was observed in the patients treated with TP [9.74 (4.98)] (Fig. 1).

\section{Redness on Scalp}

At baseline, the mean (SD) redness of the scalp was $0.09(0.22), 0.10(0.22)$, and $0.13(0.24)$ in patients treated with RP1, RP2, and TP, respectively. At day 15, no change in mean (SD) score for redness was observed in RP1 [0.08 (0.15)] or RP2 [0.13 (0.21)] group compared with baseline. A significant decrease ( $p$-value, 0.005) in the mean (SD) score for redness was observed in the TP group (0) compared with baseline. Similar to day 15 , no change in the mean score for redness was observed in the RP1 [0.08 (0.13)] or RP2
[0.11 (0.17)] groups at day 30 compared with baseline. A significant decrease ( $p$-value, 0.009) in the mean (SD) score for redness was observed in the TP group [0.01 (0.04)] at day 30 compared with baseline (Fig. 2). The proportion of patients with minimal redness increased from baseline to day 30 in the RP1 (16.7-26.7\%) and RP2 (21.2-33.3\%) groups, while a decrease was observed in the TP (29.0-3.2\%) group (Fig. 2).

\section{Dryness/Scaling on Scalp}

At baseline, the mean (SD) redness of the scalp was 0.09 (0.26), 0.05 (0.18), and 0.01 (0.04) in patients treated with RP1, RP2, and TP, respectively. After 15 days of treatment, there was a significant decrease ( $p$ value, 0.049 ) in the mean 


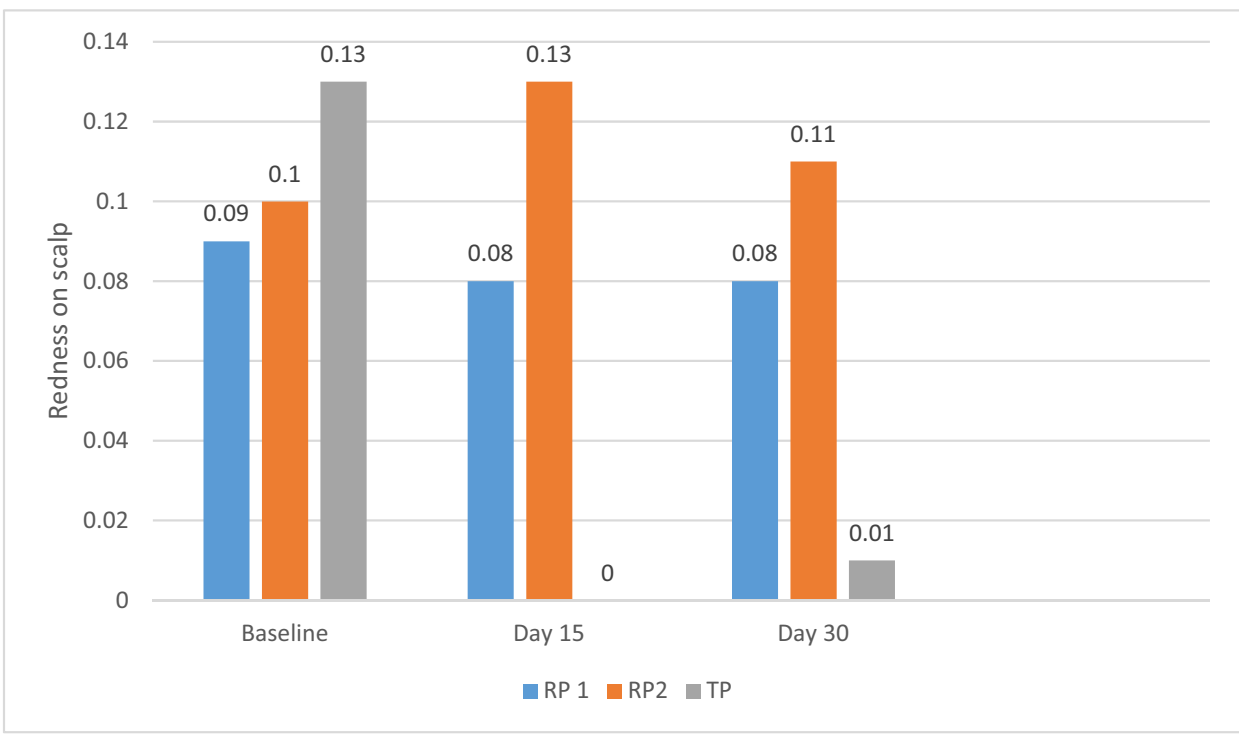

\begin{tabular}{|c|c|c|c|}
\hline & RP1 $(n=30)$ & RP2 $(n=33)$ & TP $(\mathbf{n}=31)$ \\
\hline & \multicolumn{3}{|c|}{ Mean (SD) redness content on the scalp } \\
\hline Baseline & $0.09 \pm 0.22$ & $0.10 \pm 0.22$ & $0.13 \pm 0.24$ \\
\hline Day 15 & $0.08 \pm 0.15$ & $0.13 \pm 0.21$ & $0.00 \pm 0.00$ \\
\hline \multirow[t]{2}{*}{ Day 30} & $0.08 \pm 0.13$ & $0.11 \pm 0.17$ & $0.01 \pm 0.04$ \\
\hline & \multicolumn{3}{|c|}{ Mean (SD) change from baseline } \\
\hline Day 15, (p value) & $\begin{array}{l}-0.02 \pm 0.15 \\
(0.471) \mathrm{NS}\end{array}$ & $\begin{array}{l}0.03 \pm 0.20 \\
(0.395) \mathrm{NS}\end{array}$ & $\begin{array}{l}*_{-0.13 \pm 0.24} \\
(0.005)\end{array}$ \\
\hline \multirow[t]{2}{*}{ Day 30, ( $\mathrm{p}$ value) } & $\begin{array}{l}-0.02 \pm 0.23 \\
(0.637) \mathrm{NS}\end{array}$ & $\begin{array}{l}0.01 \pm 0.24 \\
(0.812) \mathrm{NS}\end{array}$ & $\begin{array}{l}*_{-} 0.12 \pm 0.24 \\
(0.009)\end{array}$ \\
\hline & \multicolumn{3}{|c|}{ Redness score, $n$ (\%) } \\
\hline \multicolumn{4}{|l|}{ Baseline } \\
\hline 0 & $24(80)$ & $25(75.7)$ & $21(67.7)$ \\
\hline$>0-<1$ & $5(16.7)$ & $7(21.2)$ & $9(29.0)$ \\
\hline 1 & $1(3.3)$ & 1 & $1(3.2)$ \\
\hline \multicolumn{4}{|l|}{ Day 15} \\
\hline 0 & $23(76.7)$ & $22(66.7)$ & $31(100)$ \\
\hline$>0-<1$ & $7(23.3)$ & $11(33.3)$ & 0 \\
\hline$=1$ & $0(3.0)$ & 0 & 0 \\
\hline \multicolumn{4}{|l|}{ Day 30} \\
\hline 0 & $22(73.3)$ & $22(66.7)$ & $30(96.8)$ \\
\hline$>0-<1$ & $8(26.7)$ & $11(33.3)$ & $1(3.2)$ \\
\hline 1 & 0 & 0 & 0 \\
\hline
\end{tabular}

Fig. 2 Mean change from baseline in redness on scalp (table with redness score included below figure)

(SD) score of scaling in the RP1 [0.07 (0.20)] group compared with baseline. No significant difference was observed in the mean score of scaling in the RP2 [0.04 (0.18)] or TP $[0(0)]$ group compared with baseline. After 30 days of treatment, no significant difference was 


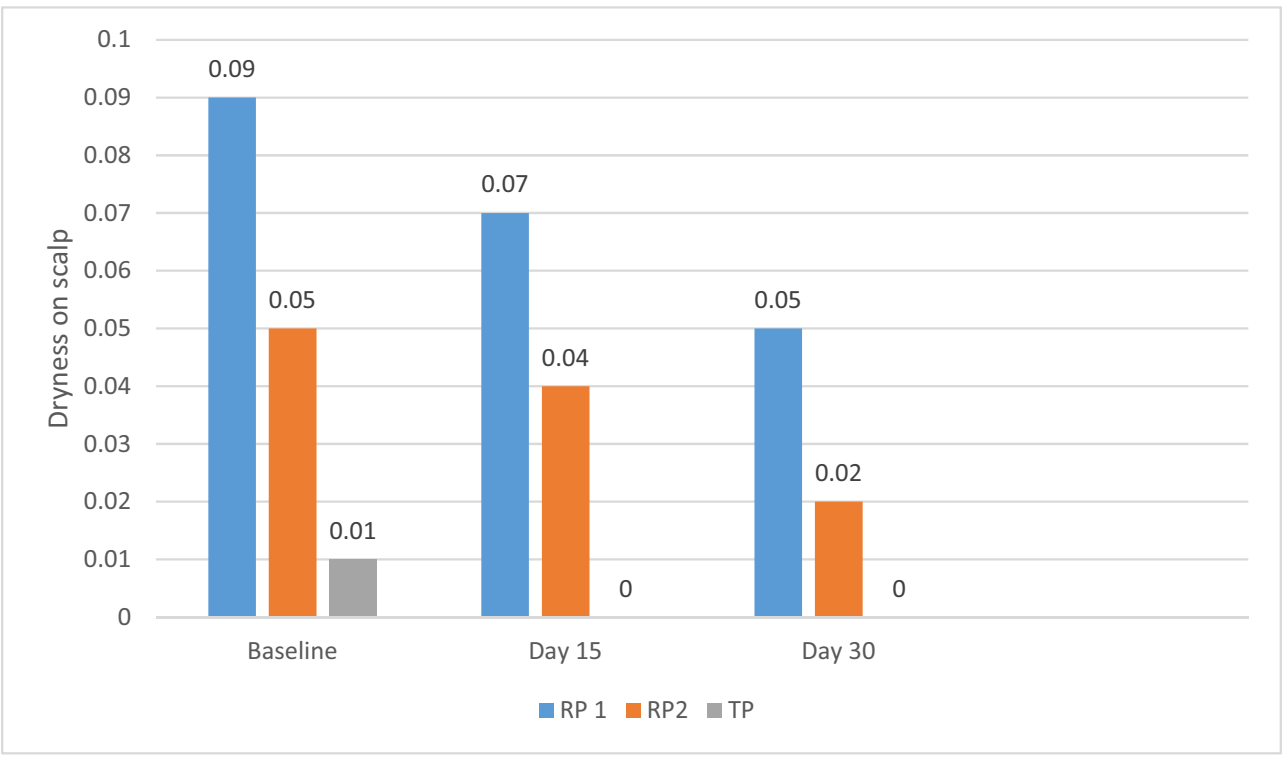

\begin{tabular}{|c|c|c|c|}
\hline & RP1 (n= 30) & RP2 $(n=33)$ & TP $(n=31)$ \\
\hline \multicolumn{4}{|c|}{ Mean (SD) redness content on the scalp } \\
\hline Baseline & $0.09 \pm 0.26$ & $0.05 \pm 0.18$ & $0.01 \pm 0.04$ \\
\hline Day 15 & $0.07 \pm 0.20$ & $0.04 \pm 0.18$ & $0.00 \pm 0.00$ \\
\hline Day 30 & $0.05 \pm 0.17$ & $0.02 \pm 0.06$ & $0.00 \pm 0.00$ \\
\hline \multicolumn{4}{|c|}{ Mean (SD) change from baseline } \\
\hline Day $15,(\mathrm{p}$ value) & $\begin{array}{l}*_{-} 0.03 \pm 0.08 \\
(0.049)\end{array}$ & $\begin{array}{l}-0.02 \pm 0.06 \\
(0.064) \mathrm{NS}\end{array}$ & $\begin{array}{l}-0.01 \pm 0.04 \\
(0.174) \mathrm{NS}\end{array}$ \\
\hline Day $30,(p$ value) & $\begin{array}{l}-0.04 \pm 0.12 \\
(0.078) \mathrm{NS}\end{array}$ & $\begin{array}{l}-0.04 \pm 0.14 \\
(0.110) \mathrm{NS}\end{array}$ & $\begin{array}{l}-0.01 \pm 0.04 \\
(0.174) \mathrm{NS}\end{array}$ \\
\hline \multicolumn{4}{|c|}{ Dryness score, $\mathbf{n}(\%)$} \\
\hline \multicolumn{4}{|l|}{ Baseline } \\
\hline 0 & $25(83.3)$ & $29(87.9)$ & $30(96.8)$ \\
\hline$>0-<1$ & $3(10.0)$ & $3(9.1)$ & $1(3.2)$ \\
\hline 1 & $2(6.7)$ & $1(3.0)$ & 0 \\
\hline \multicolumn{4}{|l|}{ Day 15} \\
\hline 0 & $26(86.7)$ & $31(94.0)$ & $31(100)$ \\
\hline$>0-<1$ & $4(13.3)$ & $1(3.0)$ & 0 \\
\hline$=1$ & 0 & $1(3.0)$ & 0 \\
\hline \multicolumn{4}{|l|}{ Day 30} \\
\hline 0 & $27(90.0)$ & $31(93.9)$ & $31(100)$ \\
\hline$>0-<1$ & $3(10.0)$ & $2(6.1)$ & 0 \\
\hline 1 & 0 & 0 & 0 \\
\hline
\end{tabular}

NS, not significant; * significant.

RP1, 5\% Regaine; RP2, 5\% Mintop Forte; TP, test minoxidil 5\% novel formulation 0 , no scaling, $>0-<1$, minimal scaling, 1 , very slight scaling.

Fig. 3 Mean change from baseline in dryness on scalp (table with dryness score included below figure)

observed in the mean score of scaling in any of the three groups. All the patients treated with
TP were without scaling at days 15 and 30 (Fig. 3). 


\section{In-Use Skin Tolerance (Itching, Burning, and Prickling)}

The proportion of patients who reported no itching at days 15 and 30 was significantly higher in the TP group ( $p$-value $<0.05)$ compared with the RP1 and RP2 groups (RP1 versus RP2 versus TP; day 15: 80\%, 72.7\%, and 96.8\%; day 30: $86.7 \%, 84.8 \%$, and $100 \%)$. The proportion of patients who reported no burning at days 15 and 30 was higher in the TP group compared with the RP1 and RP2 groups (RP1 versus RP2 versus TP; day 15: 93.3\%, 97\%, and 100\%; day 30: 96.7\%, 93.3\%, and 100\%). At day $15,86.7 \%, 81.8 \%$, and $90.3 \%$ patients reported no prickling sensation in the RP1, RP2, and TP groups, respectively. At day 30, 93.9\%, 81.8\%, and $90.3 \%$ patients reported no prickling sensation in the RP1, RP2, and TP groups, respectively (Table 2).

Three patients in the RP1 group and five patients in the RP2 group were not satisfied with the product in terms of tolerability; however, all the patients in the TP group were satisfied. No adverse events or deaths were reported in this study. Overall, $46.7 \%$ of the patients using RP1, 75.8\% of patients using RP2, and $100 \%$ of patients using TP reported that the fragrance was pleasant to good (Table 3).

\section{DISCUSSION}

This comparative study aimed to evaluate the in-use tolerance of a minoxidil 5\% topical solution (TP) novel formulation versus currently marketed alcohol-based 5\% minoxidil topical solutions (RP1 and RP2) in Indian men with androgenetic alopecia. The 30-day trial clearly demonstrated that, compared with alcohol-based 5\% minoxidil solution, the 5\% minoxidil novel formulation was safer, showed better in-use tolerability, and was more acceptable in patients with androgenetic alopecia.

This study was conducted in Nashik (Maharashtra, India) during the winter season (December 2018 to February 2019), with temperature ranging from $32{ }^{\circ} \mathrm{C} / 19{ }^{\circ} \mathrm{C}$ to $30^{\circ} \mathrm{C} /$ $16^{\circ} \mathrm{C}$ and relative humidity $(\mathrm{RH})$ ranging from $40 \%$ to $70 \%$. Studies where skin moisture is measured should be avoided during the summer
Table 2 Proportion of patients with itching, burning, and prickling sensation following minoxidil treatment

\begin{tabular}{llll}
\hline Scoring, & RP1 & RP2 & TP \\
$n(\%)$ & $(n=30)$ & $(n=33)$ & $(n=31)$ \\
\hline
\end{tabular}

Itching

Day 15

$\begin{array}{llll}\text { None } & 24(80) & 24(72.7) & 30(96.8)^{*} \\ \text { Mild } & 6(20) & 9(27.3) & 1(3.2) \\ \text { Moderate } & 0 & 0 & 0 \\ \text { Severe } & 0 & 0 & 0\end{array}$

Day 30

$\begin{array}{llll}\text { None } & 26(86.7) & 28(84.8) & 31(100)^{*} \\ \text { Mild } & 3(10) & 5(15.2) & 0 \\ \text { Moderate } & 1(3.3) & 0 & 0 \\ \text { Severe } & 0 & 0 & 0\end{array}$

Burning

Day 15

$\begin{array}{llll}\text { None } & 28(93.3) & 32(97.0) & 31(100)^{\#} \\ \text { Mild } & 2(6.7) & 1(3.0) & 0 \\ \text { Moderate } & 0 & 0 & 0 \\ \text { Severe } & 0 & 0 & 0\end{array}$

Day 30

$\begin{array}{llll}\text { None } & 29(96.7) & 31(93.9) & 31(100)^{\#} \\ \text { Mild } & 1(3.3) & 2(6.1) & 0 \\ \text { Moderate } & 0 & 0 & 0 \\ \text { Severe } & 0 & 0 & 0\end{array}$

Prickling

Day 15

$\begin{array}{llll}\text { None } & 26(86.7) & 27(81.8) & 28(90.3)^{\#} \\ \text { Mild } & 4(13.3) & 6(18.2) & 3(9.7) \\ \text { Moderate } & 0 & 0 & 0 \\ \text { Severe } & 0 & 0 & 0\end{array}$

Day 30

\begin{tabular}{llll} 
None & $28(93.3)$ & $27(81.8)$ & $28(90.3)^{\#}$ \\
Mild & $2(6.7)$ & $6(18.2)$ & $3(9.7)$ \\
\hline
\end{tabular}


Table 2 continued

\begin{tabular}{llll}
\hline $\begin{array}{l}\text { Scoring, } \\
n(\%)\end{array}$ & $\begin{array}{l}\text { RP1 } \\
(n=30)\end{array}$ & $\begin{array}{l}\text { RP2 } \\
(n=33)\end{array}$ & $\begin{array}{l}\text { TP } \\
(n=31)\end{array}$ \\
\hline Moderate & 0 & 0 & 0 \\
Severe & 0 & 0 & 0 \\
\hline
\end{tabular}

RP1 5\% Regaine, RP2 5\% Mintop Forte, TP test minoxidil $5 \%$ novel formulation

${ }^{*} p<0.05$, significant, ${ }^{*} p>0.05$, not significant

Table 3 Proportion of patients with satisfied tolerability following minoxidil treatment

\begin{tabular}{llll}
\hline$n(\%)$ & $\mathrm{RP1}$ & $\mathrm{RP2}$ & $\mathrm{TP}$ \\
& $(n=30)$ & $(n=33)$ & $(n=31)$ \\
\hline
\end{tabular}

Satisfied tolerability

$\begin{array}{llll}\text { Satisfied } & 27(90) & 28(85) & 31(100) \\ \text { Not satisfied } & 3(100) & 5(15) & 0\end{array}$

Fragrance acceptability

\begin{tabular}{llll} 
Terrible & 0 & 0 & 0 \\
Bad & 0 & 0 & 0 \\
Unpleasant & $2(6.7)$ & 0 & 0 \\
Acceptable & $14(46.7)$ & $8(24.2)$ & 0 \\
Pleasant & $14(46.7)$ & $19(57.6)$ & $8(25.8)$ \\
Good & 0 & $6(18.2)$ & $23(74.2)$ \\
$\begin{array}{l}\text { Pleasant- } \\
\text { good) }\end{array}$ & $14(46.7)$ & $25(75.8)$ & $31(100)$ \\
\hline
\end{tabular}

RP1 5\% Regaine, RP2 5\% Mintop Forte, TP test minoxidil $5 \%$ novel formulation

season due to large climatic variations [11]. Skin is driest in winter, and these conditions are suitable to magnify any intolerances such as dryness, itching, and redness [12].

Alcohol-containing topical solutions including minoxidil are known to cause dryness of the skin/scalp [7, 8]. Dryness of the scalp is caused due to loss of moisture from stratum corneum, leading to low skin hydration. MoistureMeter SC readings indicated that the alcohol-based minoxidil solutions RP1 and RP2 significantly decreased ( $p$-value, 0.001 ) the moisture content of the scalp, which led to the drying of the scalp, whereas minoxidil novel formulation solution (TP) significantly ( $p$-value, 0.001) improved the hydration of the scalp. There was no significant difference in the scalp dryness when assessed visually. This may be due to the fact that visual assessment is a semiobjective method of evaluation and may not capture minute changes as detected by a MoistureMeter SC reading. The MoistureMeter apparatus is suitable for quantitative evaluation of shortand long-term hydration effects on the skin $[13,14]$.

Loss of moisture usually leads to itching of the scalp [15]. The proportion of patients who reported no itching on day 30 was significantly greater in the TP group as compared with the RP1 and RP2 groups. This correlates well with the MoistureMeter SC readings that suggested an improvement in scalp hydration in patients treated with TP for 30 days, which resulted in decreased itching. The 5\% minoxidil solutions RP1 and RP2 showed a decrease in scalp hydration, which was reflected in the increased proportion of patients with itching.

Owing to the itching due to dry skin, patients using alcohol-based formulations usually report redness of the scalp $[7,8]$. In this study, patients treated with 5\% minoxidil novel formulation showed a significant decrease in redness after 30 days of treatment, while the alcohol-based formulations showed no difference in the mean redness of the scalp. This could be due to the less itching and increased scalp hydration in the minoxidil novel formulation solution group. No significant differences were observed between the three groups in terms of the proportion of patients reporting prickling and burning sensation after 30 days of treatment.

The local irritation caused by the alcoholbased topical solutions affects patients' self-tolerability and impacts patients' compatibility and adherence to the treatment in the long term [10]. In this study, all the patients treated with 5\% minoxidil novel formulation reported satisfactory tolerability, treatment satisfaction, and fragrance acceptability, which would 
improve patients' adherence to the treatment in the long term. No other safety findings were reported in this study in any of the three treatment groups. The efficacy of the novel minoxidil formulation was not evaluated, which is a limitation of this study. Also, the efficacy and safety of the novel minoxidil formulation with low alcohol content was not compared with other minoxidil preparations containing higher alcohol content as formulation vehicle.

\section{CONCLUSIONS}

The minoxidil novel formulation showed a significant improvement in hydration and reduced the dryness, redness, and itching of the scalp, whereas alcohol-based formulations increased the dryness and redness of the scalp after 15 and 30 days of treatment in men with androgenetic alopecia. This study also demonstrated that the novel minoxidil formulation was better tolerated compared with alcoholic formulations. Hence, the novel minoxidil formulation could be a safer and most satisfactory alternative to alcoholic formulations in treating men with androgenetic alopecia.

\section{ACKNOWLEDGEMENTS}

We thank Preethi Bheereddy M.S (Pharm) and Priyanka Sharma M.Pharm, SIRO ClinPharm (funded by DRL) for editorial and graphics support. The authors also thank the study participants, without whom this study would not have been accomplished, and the investigators and investigator site team at C.L.A.I.M.S. Pvt. Ltd. for their support in this study.

Funding. This research was funded by Dr. Reddy's Laboratories Ltd., which also funded the journal's rapid service fee.

Authorship. All named authors meet the International Committee of Medical Journal Editors (ICMJE) criteria for authorship for this article, take responsibility for the integrity of the work as a whole, and have given their approval for this version to be published.
Disclosures. Dr. Suneel Vartak is a consultant dermatologist and principal investigator at C.L.A.I.M.S. Pvt. Ltd. Dr. Amey Mane, Dr. Suyog Mehta, and Dr. Sujeet Narayan Charugulla are employees of Dr Reddy's Laboratories Ltd. Dr. Shivani Acharya and Dr. Nikhil Kumar Kursam were employed by Dr. Reddy's Laboratories Ltd at the time of the study. Dr. Rashmi Sarkar has nothing to disclose.

Compliance with Ethics Guidelines. The study protocol and informed consent form were reviewed and approved by Independent Ethics Committee and Institutional Review Board (registration no. ECR/98/Inst/MH/2013/RR-16; Yash Society's Sujata Birla Hospital Ethics Committee, Nashik Road). The study was in compliance with the ethical principles of the Declaration of Helsinki and was conducted in accordance with the International Council for Harmonization, Good Clinical Practice guidelines, and schedule Y. This study is registered prospectively at Clinical Trial Registry of India (CTRI/2018/11/016431).

Data Availability. The data can be provided by the authors upon reasonable request.

Open Access. This article is licensed under a Creative Commons Attribution-NonCommercial 4.0 International License, which permits any non-commercial use, sharing, adaptation, distribution and reproduction in any medium or format, as long as you give appropriate credit to the original author(s) and the source, provide a link to the Creative Commons licence, and indicate if changes were made. The images or other third party material in this article are included in the article's Creative Commons licence, unless indicated otherwise in a credit line to the material. If material is not included in the article's Creative Commons licence and your intended use is not permitted by statutory regulation or exceeds the permitted use, you will need to obtain permission directly from the copyright holder. To view a copy of this licence, visit http://creativecommons.org/licenses/by$\mathrm{nc} / 4.0 /$. 


\section{REFERENCES}

1. Krupa Shankar D, Chakravarthi M, Shilpakar R. Male androgenetic alopecia: population-based study in 1005 subjects. Int J Trichol. 2009;1(2): 131-3.

2. Varothai S, Bergfeld WF. Androgenetic alopecia: an evidence-based treatment update. Am J Clin Dermatol. 2014;15(3):217-30.

3. Hunt N, McHale S. The psychological impact of alopecia. BMJ (Clin Res Ed). 2005;331(7522):951-3.

4. Olsen EA, Whiting D, Bergfeld W, et al. A multicenter, randomized, placebo-controlled, doubleblind clinical trial of a novel formulation of $5 \%$ minoxidil topical foam versus placebo in the treatment of androgenetic alopecia in men. J Am Acad Dermatol. 2007;57(5):767-74.

5. Thomas J. Androgenetic alopecia-current status. Indian J Dermatol. 2005;50(4):179.

6. Blumeyer A, Tosti A, Messenger A, et al. Evidencebased (S3) guideline for the treatment of androgenetic alopecia in women and in men. JDDG: Journal der Deutschen Dermatologischen Gesellschaft. 2011;9:S1-S57.

7. Rossi A, Cantisani C, Melis L, et al. Minoxidil use in dermatology, side effects and recent patents. Recent Pat Inflamm Allergy Drug Discov. 2012;6(2):130-6.

8. Blume-Peytavi U, Issiakhem Z, Gautier S, et al. Efficacy and safety of a new $5 \%$ minoxidil formulation in male androgenetic alopecia: A randomized, placebo-controlled, double-blind, noninferiority study. J Cosmet Dermatol. 2019;18(1): 215-20.

9. Olsen EA, Dunlap FE, Funicella T, et al. A randomized clinical trial of 5\% topical minoxidil versus $2 \%$ topical minoxidil and placebo in the treatment of androgenetic alopecia in men. J Am Acad Dermatol. 2002;47(3):377-85.

10. Trüeb RM. North American Virginian witch hazel (Hamamelis virginiana): based scalp care and protection for sensitive scalp, red scalp, and scalp burnout. Int J Trichol. 2014;6(3):100.

11. Barel A, Clarys P, Gabard B. In vivo evaluation of the hydration state of the skin: measurements and methods for claim support in cosmetics. Berlin: Springer; 1999. p. 57-80.

12. Guenther L, Lynde CW, Andriessen A, et al. Pathway to dry skin prevention and treatment. J Cutan Med Surg. 2012;16(1):23-31.

13. Barel AO, Clarys P. Measurement of epidermal capacitance. In: Serup J, Jemec GBE, Grove GL, editors. Handbook of non-invasive methods and the skin. Florida: CRC Press; 2006. p. 337-44.

14. Lakhani R, Prakash C, Tiwari S, et al. Scoring system in dermatology: a review. IOSR J Dent Med Sci. 2016;15(7):89-99.

15. Marenus KD. Skin conditioning benefits of moisturizing products. Cosmetic claims substantiation. Boca Raton: CRC Press; 1997. p. 113-130. 